UNIVERSITY OF GOTHENBURG

SCHOOL OF BUSINESS, ECONOMICS AND LAW

WORKING PAPERS IN ECONOMICS

No 655

\title{
Public Goods and Minimum Provision Levels Does the institutional formation affect cooperation?
}

\author{
Peter Martinsson and Emil Persson
}

April 2016

ISSN 1403-2473 (print)

ISSN 1403-2465 (online) 


\title{
Public Goods and Minimum Provision Levels Does the institutional formation affect cooperation?
}

\author{
Peter Martinsson ${ }^{*}$ \\ Department of Economics, University of Gothenburg, Sweden \\ Emil Persson ${ }^{\dagger}$ \\ Centre for Research Ethics \& Bioethics, Uppsala University, Sweden \\ Department of Economics, University of Gothenburg, Sweden
}

\begin{abstract}
We investigate the role of institutional formation on the implementation of a binding minimum contribution level in a linear public goods game. Groups either face the minimum level exogenously imposed by a central authority or are allowed to decide for themselves by means of a group vote whether or not a minimum level should be implemented. We find a binding minimum contribution level to have a positive and substantially significant effect on cooperation. The main impact is on the extensive margin, meaning that it is possible to force free riders to increase their contribution without crowding out others' voluntary contributions. This result is robust to the mode of implementation and thus when the minimum level is enforceable, it is a simple policy that will increase provision of the public good.
\end{abstract}

Keywords: Public goods, Minimum level, Voting, Experiment.

JEL Classification: C91, D72, H41.

\footnotetext{
* Department of Economics, University of Gothenburg, Box 640, SE-40530 Gothenburg, Sweden; Tel.: +46 31 786 5255; E-mail: peter.martinsson@economics.gu.se.

${ }^{\dagger}$ Centre for Research Ethics \& Bioethics, Uppsala University, Box 564, SE-75122 Uppsala, Sweden; Tel.: +46 18471 6288; E-mail: emil.persson@crb.uu.se. (Corresponding author.)
} 


\section{Introduction}

Free riding is a frequently discussed reason for creating institutions to increase contributions to public goods. To reduce the problem of under-provision of public goods, formal institutions are often established. Many of these institutions focus specifically on the free riders or those who contribute a small amount to the public good for example by allowing punishment (e.g., see overview in Chaudhuri, 2011). ${ }^{1}$ In real life, however, the most frequently used institution to combat free riders is to require some minimum contribution level. For example when it comes to the environment, there are certain standards for emissions from cars and for recycling at household level. Entrance fees to museums or national parks, and workload in teams, are other examples. The most common example is probably the financing of public goods such as health care and schools through taxation. The focus of this paper is whether a minimum level per se helps to increase contributions to a public good. Alternatively, these public goods could be provided in a regime without any minimum standards for cars or entrance fees, and rely solely on voluntary contributions. From an institutional design point of view, the question is whether a binding minimum level results in crowding out and whether the way the institution is implemented affects contribution levels. The objective of this paper is to investigate, by using a public goods experiment, the effect (i) of imposing a minimum contribution level for a public good and (ii) of the mode of implementation, i.e., whether the way the minimum level is introduced, either endogenously by majority voting or exogenously, affects contributions.

Binding minimum contribution levels have been studied experimentally with mixed results in terms of how levels of contributions to public goods have been affected. For instance, Andreoni (1993) and Gronberg et al. (2012) find that minimum levels increase contributions in public goods games with concave payoff functions and Chan et al. (2002) find the same effect but furthermore that it wears off as the minimum level is increased. Conversely, Kocher et al. (2016) implement minimum levels in a linear public goods game, and for a low minimum level they find no effect on public good provision whereas for a higher minimum level they find an overall positive effect. Moreover, the effects are qualitatively similar when the minimum level is endogenously imposed by one randomly selected group member. Keser et al. (2014) investigate minimum levels in a linear public goods experiment with endowment

\footnotetext{
${ }^{1}$ There are also experiments focusing on incentivizing people to give a high amount by allowing rewards (e.g., Sefton et al., 2007).
} 
heterogeneity and find that the minimum level increases public good provision if subjects with a higher endowment face a higher minimum level. ${ }^{2}$ Furthermore, a recent set of interesting papers use minimum levels to study strategic aspects of international negotiations concerning global public goods provision (e.g., climate protection). For example, Dannenberg (2012) and Dannenberg et al. (2014) study coalition formation in light of subsequent introduction of a minimum contribution level within this coalition, and Kesternich et al. (2014a,b) and Gallier et al. (2014) implement minimum contribution levels in settings where subjects are heterogeneous with respect to their endowment or their marginal per capita return from the public good. ${ }^{3}$ Common among the latter set of papers is the feature that subjects simultaneously propose a minimum contribution level and the lowest level proposed is subsequently implemented.

When a minimum level is introduced, subjects who contribute below this level need to increase their contributions at least to the imposed level. But how do subjects who contribute to the public good above the minimum level even in the absence of such a mechanism react when the minimum level is implemented? These subjects could be crowded out, meaning that they voluntary decrease their contribution to the public good, e.g., from $50 \%$ to $40 \%$ of their endowment, or they could be crowded in, meaning that they voluntary increase their contribution to the public good, e.g., from $50 \%$ to $60 \%$ of their endowment. One reason for the latter effect could be that subjects are conditional cooperators, i.e., they want to cooperate if others cooperate and vice versa (e.g., Fischbacher et al., 2001) and therefore they increase their public good contribution since free riders are forced to increase their contribution at least up to the imposed minimum level. Several factors could result in crowding out. The implemented minimum level could serve as a focal point regarding which contribution level is expected. This could affect people in two ways: either directly by making them choose to contribute the minimum level or indirectly by making them believe that other group members will see the minimum level as a focal point. Crowding out could also be due to a "hidden cost of control," i.e., subjects do not like the control exerted upon them and therefore reduce their contribution. Falk and Kosfeld (2006) and Ziegelmeyer et al. (2012) implement principalagent experiments where agents receive a fixed wage and can choose to engage in a production activity that is costly to the agent but beneficial to the principal; the "hidden cost

\footnotetext{
${ }^{2}$ For public goods experiments using non-binding minimum levels, see, e.g., Galbiati and Vertova (2008) and Riedel and Schildberg-Hörisch (2013).

${ }^{3}$ A related paper is Gerber et al. (2013), who examine minimum requirements with respect to formation of the coalition itself.
} 
of control” amounts to the degree to which agents reduce their efforts when the principal implements a minimum performance requirement. The effect is strong in the former study but somewhat weaker in the latter (where it is dominated by the positive effect of forcing lowperforming agents to increase their effort). This effect is potentially magnified by subjects' beliefs about others' reactions following the introduction of the minimum contribution level.

If hidden costs of control are pervasive, there is a risk that they will partly or even completely offset the direct effect of the minimum contribution level (forcing free riders to increase their contribution). In this case, legitimizing the minimum level by granting local decision rights to groups may be critical in order to achieve a more successful outcome. We test this by allowing groups to decide for themselves whether or not the minimum level should be implemented. In more detail, we study experimentally the implementation of a minimum contribution level in a linear public goods game. ${ }^{4}$ Groups either face the minimum level exogenously imposed by a central authority or are allowed to choose whether or not to implement it based on the outcome of majority voting.

A growing experimental literature examines how centralized institutions with exogenous power to implement policies can increase cooperation in social-dilemma situations. In this setting, the degree of crowding out due to hidden costs of control and whether it can be alleviated through endogenous institutional formation is still an open empirical question, which we address in the current paper. We find a minimum contribution level to have a positive and substantial effect on cooperation. The main impact is on the extensive margin, meaning that it is possible to force free riders to increase their contribution without crowding out others' voluntary contributions. This result is robust to the mode of implementation; that is, exogenous minimum levels are as effective as endogenous minimum levels. This result stands in contrast to several recent papers documenting that endogenously chosen institutions do alleviate collective-action problems to a larger extent than when the same institutions are exogenously imposed. Tyran and Feld (2006) let subjects vote on the introduction of a law that prescribes full contribution to the public good. They find that a "mild law," which is

\footnotetext{
${ }^{4}$ The main difference between our design using a linear payoff function and other experimental studies of minimum levels that instead use concave payoff functions (e.g., Andreoni, 1993; Chan et al., 2002; Gronberg et al., 2012) is that the minimum level is set above rather than below the Nash equilibrium. This is important since we want to consider the issue of conditional cooperation in combination with hidden costs of control and these potential effects become more salient with linear payoff functions. Papers using concave payoff functions have studied a different question, namely the neutrality of government spending with respect to privately provided public goods (Warr, 1982; Bergstrom et al., 1986; Andreoni, 1989, 1990).
} 
backed up by a non-deterrent sanction, is more effective when chosen endogenously than when exogenously imposed. Dal Bó et al. (2010) introduce the possibility for subjects to endogenously impose a fine on unilateral defection in a prisoners' dilemma game, and find that this increases cooperation compared with the same fine exogenously imposed. Sutter et al. (2010), Markussen et al. (2014a), and Kamei et al. (2015) find that peer-to-peer punishment can sustain high levels of cooperation to a greater extent when democratically chosen than when exogenously imposed. However, Markussen et al. (2014b) find no effect of endogenous institutional choice. They investigate the effect of intergroup competition on local public good provision within groups, and find that competition is as effective if endogenously chosen as if exogenously imposed. Likewise, Sutter and Weck-Hannemann (2004) extend Andreoni (1993) by introducing endogenous taxation on public good contributions and find no positive effect on contributions compared with exogenous taxation. Taken together, the benefit of granting groups participation rights seems to be context dependent and we discuss our results in light of this in a concluding section of the paper.

A majority of the groups in the endogenous treatment in our experiment successfully implement the minimum-level institution. This is in line with several other papers that examine endogenous institutional choice and find that groups - when given the freedom of choice - successfully implement efficiency-enhancing institutions. In Kroll et al. (2007), subjects submit proposals for how much everyone should contribute to the public good. Then they vote on the proposals and if one proposal receives sufficient support it is implemented. They find that when the vote is binding, it results in high levels of public good provision. Putterman et al. (2011) let subjects vote on the parameters of a centralized punishment scheme in the context of public good provision and find that most groups are able to implement a scheme where it is optimal for everyone to contribute their entire endowment. In Markussen et al. (2014a), groups endogenously choose between different types of punishment schemes. They find that most groups are able to implement low cost and deterrent sanctions, which can increase public good provision. Kosfeld et al. (2009) implement public goods experiments where groups can form an organization in which all members must contribute their entire endowment to the public good, while subjects in the group not covered by the organization can contribute as they wish. They find that contributions and welfare are higher when groups are allowed to form organizations. Finally, in Ertan et al. (2009), subjects endogenously choose the rules for peer-to-peer punishment. They find that most groups eventually implement a scheme that allows them to achieve high levels of public good 
provision. $^{5}$

\section{Experimental design}

We use a linear public goods experiment with a design similar to the one developed by Fischbacher et al. (2001) and where the main characteristic is that the strategy method is used. Each group consists of three randomly matched members, and the marginal per capita return (MPCR) from the public good is 0.5. For a rational and selfish subject, an MPCR below one results in a dominant strategy to free ride, i.e., to contribute zero to the public good. However, since $\mathrm{MPCR}^{*} n>1$, where $n$ is number of group members, it is socially optimal to contribute the whole endowment. Thus, our choice of marginal per capita return creates the conflict between private and social optima that characterizes a public good. Each subject has an endowment of 20 tokens, and we denote $c$ the amount invested in the public good. Thus, the payoff for subject $i$ is given by

$$
\pi_{i}=20-c_{i}+0.5 \sum_{j=1}^{3} c_{j}
$$

The key difference between the Fischbacher et al. design and standard public goods experiments is that the former employs the strategy method. The subjects make two different types of decisions on how much they would like to contribute to the public good - one unconditional and one conditional. In the unconditional decision, the subject states how much she would like to contribute to the public good as in a standard public goods experiment. The conditional contribution to the public good is the amount a subject would like to contribute conditional on the other two group members' average contribution. Each subject makes 21 conditional decisions in total, one for each integer number from 0 to 20, representing all the possible (integer) averages of the other two group members. All contribution decisions are incentive compatible since the payoff-relevant decision for two randomly selected members of the group is the unconditional contribution, and by using their average unconditional contribution, the contribution of the third member is determined as the conditional contribution for that specific average contribution.

The experiment consists of two stages, both of which are based on the design by Fischbacher et al. (2001): (i) a standard public goods experiment and (ii) a public goods experiment where

\footnotetext{
${ }^{5}$ See also Dal Bó (2014) for an overview of the experimental literature on collective action and the effects of democratic institutions.
} 
a minimum contribution level is either exogenously or endogenously imposed. There are two treatments in the experiments: an exogenously imposed minimum contribution level and an endogenously imposed minimum contribution level. In the exogenous treatment, a minimum contribution level of 5 tokens is imposed, while in the endogenous treatment the implementation of a minimum level of 5 tokens is subject to a group vote. There is no cost of voting, and the voting is made mandatory. A majority rule determines the outcome, and thus if at least 2 out of the 3 group members vote for the minimum contribution level of 5 tokens it is imposed, and vice versa.

To test for the impact of a minimum contribution level, we run two types of sessions. Both of them begin with the baseline game described in the previous paragraph (and without any minimum level). In sessions with the exogenous treatment, the standard public goods experiment is followed by the same game but now exogenously imposing the rule that everyone must contribute at least 5 tokens to the public good. In sessions with the endogenous treatment, the standard public goods experiment is instead followed by a voting stage where each member casts a vote on whether or not they would like to introduce a minimum level of 5 tokens. Thus, the majority outcome of the vote determines whether or not a minimum level is imposed. This means that the baseline game is followed by either the standard public goods experiment again or the same experiment but with a minimum level of 5 tokens depending on the majority decision in the voting stage. We use perfect stranger matching and the subjects are not informed about the outcome of the first public goods experiment until the final payment is made. ${ }^{6}$ This is clearly stated in the instructions given to the subjects. ${ }^{7}$ Thus, we will be able to document the importance of participation rights if the endogenous minimum level either increases contributions to a larger extent or decreases contributions to a lesser extent than does the exogenous minimum level.

The logistics of the experiment were as follows. The standard public goods experiment was first explained and then conducted. The experiment instructions included examples and individual exercises to be solved to ensure that subjects understood the setup. Upon completion of the exercises, they were also solved in public by the experimenter in order to

\footnotetext{
${ }^{6}$ We do not test for order effects. The reason is that the imposed order is natural, in the sense that we are interested in the effect of a minimum-level policy when subjects are experienced with the baseline (voluntary contribution mechanism). This is what typically happens in reality: a collective-action problem is identified and a remedy - the minimum level - is sought and implemented. Differences across treatments are tested as the difference between within-subject estimates.

${ }^{7}$ The instructions are available from the authors upon request.
} 
facilitate understanding. Questions were answered in private throughout the experiments. The subjects were randomized into a session with either exogenous or endogenous imposition of the minimum level. The voting stage preceded the second public goods game in sessions with the endogenous treatment, where subjects were asked to vote either for or against imposition of a minimum contribution level of 5 tokens. The exogenous treatment was identical except for the voting, and thus a paragraph was excluded from the instructions, which otherwise were exactly the same. After both experiments were finished, we elicited each subject's belief about others' contributions; subjects were asked to guess the average contribution of the other group members, and correct guesses were monetarily rewarded. Note that the outcome of the public goods experiment was not revealed to the subjects until the end of the experiment. Finally, subjects answered a post-experiment questionnaire related to socio-economic background factors. The experiment was conducted in a total of six sessions at the University of Gothenburg using pen and paper. Subjects were recruited using ORSEE (Greiner, 2015). An experimental session lasted on average 90 minutes, and one token corresponded to 2 SEK (at the time of the experiment corresponding to 0.30 USD). A total of 144 subjects participated, 51 in the exogenous treatment and 93 in the endogenous treatment, ${ }^{8}$ each earning an average of 150 SEK (22.50 USD).

\section{Results}

We begin the analyses by focusing on the unconditional contributions, which are summarized in Table 1. In the standard public goods experiment, the averages of the unconditional contributions are very similar among the subjects who in the second stage were allocated to either the exogenous or the endogenous treatment, i.e., 8.35 and 8.24 tokens, respectively. The small difference in contributions is insignificant, indicating that the randomization of subjects between treatments was successful (Mann-Whitney U test; $p=0.93) .{ }^{9}$ The contribution levels in the standard public goods experiment correspond to slightly more than $40 \%$ of the endowment, which is in line with other public goods experiments (e.g., Chaudhuri, 2011; Zelmer, 2004). As expected, contribution levels are higher in the public goods experiment with minimum levels (MCL). When the minimum level is exogenously imposed, the average contribution goes up to 9.43, implying a statistically significant increase of 1.08 tokens

\footnotetext{
${ }^{8}$ We choose a larger sample size in the endogenous treatment to avoid too few groups voting in favor of imposing the minimum level.

${ }^{9}$ We report from two-sided tests throughout the paper.
} 
(Wilcoxon signed-rank test; $p=0.01$ ). In the endogenous treatment, the corresponding effect is a 0.85-unit increase in average contribution and again the effect is significant (Wilcoxon signed-rank test; $p<0.01)$.

In the endogenous treatment, the group members voted about imposing a minimum contribution level of 5 tokens. A majority of the subjects voted in favor of the minimum level. Of the 93 subjects in the endogenous treatment, 75 (81\%) voted in favor of the minimum contribution level and 18 voted against it. Correspondingly, 27 of the 31 groups (87\%) voted for imposing a minimum contribution level. Interestingly, we find that men are much more likely to vote no. Fourteen of the 18 no-voters (78\%) are men; in total, $28 \%$ of the men but only $10 \%$ of the women oppose the minimum-level institution by vote. The difference in proportions is significant at the $5 \%$ level (Kruskal-Wallis test; $p=0.03$ ).

The attractive feature of a minimum contribution level is that it forces any free riders, or low contributors, to increase their contribution up to the imposed mandatory minimum. In addition to this effect, subjects contributing more than the imposed minimum can voluntarily adjust their contribution: they are crowded in if they voluntarily increase their contribution and crowded out if they voluntarily decrease their contribution. For example, subjects could be crowded out since the minimum level can signal distrust similar to the hidden cost of control in Falk and Kosfeld (2006), or it may serve as a focal point. Conditional cooperators can also be crowded in, since the minimum level forces free riders to increase their contribution, or they can be crowded out due to the belief that others will react negatively to the hidden costs of control or due to the belief that the minimum level will serve as a focal point. Thus, the overall effect is ex-ante unclear and we analyze the effect of the minimum level conditional on the contributions in the baseline case.

The main behavioral difference between the exogenous and endogenous treatments is that the hidden costs of control can be avoided in the latter case since subjects can decide for themselves on institution formation rather than being forced to contribute the minimum level. That is, when groups are given the freedom of choice, do they on average increase their public good contribution to a larger extent than groups not given this opportunity? We investigate this by comparing the impact of a minimum provision level between the exogenous and endogenous treatments. We cannot reject the null hypothesis of no effect of endogenous institutional choice; the difference (in differences) between the treatments is 0.04 tokens in public good contributions (Mann-Whitney $\mathrm{U}$ test; $p=0.57$ ). Thus, the feature of having the 
possibility to choose institution has a zero net effect on contributions. This seems to indicate that the main driver of the result is the direct effect of increased contributions from free riders and low contributors, which we analyze in more detail below.

Result 1. Minimum contribution levels have a significantly positive effect on public good contributions.

Result 2. A majority of the groups implemented the minimum level in the endogenous treatment.

Result 3. The endogenous and exogenous treatments have similar significant positive effects on public good contributions, indicating a low net effect of hidden costs of control.

\section{Insert Table 1 about here}

Table 2 shows contributions and beliefs in the two treatments. In both the exogenous and the endogenous treatment, subjects increase their belief about others' contribution when the minimum level is implemented (Wilcoxon signed-rank tests; $p<0.01$ in either case). One advantage in the endogenous treatment is that subjects are free to decide whether or not to impose the minimum level. If the hidden cost of control is expected to be a substantial problem in the case of exogenous minimum levels, there are mainly two positive effects of endogenous formation of (minimum-level) institutions. First, if individuals value the freedom of choice per se, the hidden cost of control might be overall reduced when groups are granted the right to decide for themselves whether or not to introduce minimum levels. Second, some individuals might be more control averse than others. Thus, by allowing for endogenous formation of minimum-level institutions, those groups where the exogenous minimum level would be most likely to crowd out voluntary contributions are allowed to endogenously opt out, by voting against the implementation.

The bottom panel of Table 2 shows the changes in contributions and beliefs by voting and group decision in the endogenous treatment. By and large, subjects should vote yes unless they believe that contributions were already at substantial levels ("high beliefs" hereafter) in the baseline (or if they are risk averse and uncertain about the accuracy of their high beliefs) or they have a strong aversion against control. ${ }^{10} \mathrm{~A}$ yes-vote signals that individuals are (i)

\footnotetext{
${ }^{10}$ To a selfish player with high beliefs, the minimum level will only have a direct effect on own contributions (which she will be forced to increase), and, furthermore, a yes-vote does not work as a "bait strategy" since
} 
selfish and believe that others contribute at low levels (the minimum level is a Pareto improvement), (ii) conditional cooperators who believe that others contribute at low levels (the minimum level enforces conditional cooperation at higher contribution levels), and/or (iii) not strongly averse to control. Thus, in a Yes-Yes group (“yes” for own and group vote, respectively), we expect an increase in both contributions and beliefs about others' contributions, since subjects who vote yes are either selfish or conditional cooperators and either type would respond by an increase in contributions and believe that others in the group do the same. This is what we see in Table 2: For the 72 individuals who voted yes and ended up in a group where the majority voted yes, contributions and beliefs significantly increase following the implementation of the minimum level (Wilcoxon signed-rank tests; $p<0.01$ in either case). No-voters who nevertheless end up in a group where the majority voted yes (NoYes) face the same restriction ex-post, i.e., the minimum level. For these individuals, the impact on own contributions should be negative if the individual voted no due to a strong aversion against control, but not if the no-vote was due to a fear that others in the group were averse toward control, since they seem not to be since they voted yes. The predicted change in contribution is thus ambiguous for this group, and we cannot reject a null hypothesis of no change when the minimum level is implemented (Wilcoxon signed-rank test; $p=0.63$ ). In neither of the two bottom rows of the table (No-No and Yes-No) do we expect much of a change in contributions or beliefs since the minimum level is not implemented. This is also in line with the results in the table. ${ }^{11}$

We have argued that the hidden cost of control is the main reason for voting against the minimum level, either directly or indirectly due to a fear that others will react negatively, and find that the results in Table 2 point in this direction since subjects in Yes-Yes groups on average increase their contributions under minimum levels more than subjects in No-Yes groups. Interestingly, No-Yes groups do not increase their contributions more than No-No

conditional cooperators are already contributing substantially (according to her belief). To a conditional cooperator with high beliefs, the minimum level will not have a strong direct effect on others' contributions since according to her belief, nobody is free riding. Furthermore, a subject with high beliefs about others' contributions might be more likely to fear that others will be crowded out due to the hidden costs of control (and therefore vote no). However, if subjects are uncertain about the accuracy of their beliefs, risk-averse individuals might still vote yes in order to hedge against the possibility that their high beliefs are wrong.

${ }^{11}$ In No-No groups, the minimum level is not implemented and this is in line with the own vote (the subject got what she wanted). In Yes-No groups, if the individual is a pessimistic conditional cooperator (and hence voted yes), there is no expected increase in others' contributions to respond to, and if the individual was selfish and voted yes because of an expected increase in everyone's contributions, we would not expect a behavioral response regardless (we would only expect a forced increase in contributions if the minimum level were to be implemented). 
groups even though in the former, free riders and low contributors are forced to contribute at least at the minimum level.

\section{Insert Table 2 about here}

Result 4. When a group majority decides to implement the minimum contribution level, subjects voting yes increase their contributions significantly more than subjects voting no, while there is no significant difference in contribution behavior between the two groups of voters in the standard public goods experiment.

Subjects could be crowded out or crowded in by the minimum level and here we investigate this issue in more detail. We plot individual contributions before and after the minimum provision level is imposed in the exogenous (Figure 1) and endogenous (Figure 2) treatments, respectively. ${ }^{12}$ In the figures, on the x-axis we show contribution in the standard public goods game, while on the y-axis we show the contribution when the minimum level is imposed. Any observation below the 45-degree line shows a higher contribution in the baseline than when the minimum level is imposed, i.e., crowding out, whereas any observation above the 45degree line shows crowding in for subjects who contributed at least 5 tokens in the baseline, i.e., the imposed minimum level. The figures indicate substantial individual heterogeneity as to whether subjects are crowded in, crowded out, or unaffected by the minimum level.

\section{Insert Figures 1 and 2 about here}

Tables $3-5$ add more detailed information. Table 3 shows that $49 \%$ and $43 \%$ increased their contribution under the minimum level in the exogenous and endogenous treatment, respectively, and this corresponds to the number of observations above the 45-degree line in Figures 1 and 2. Conversely, 20\% and 17\% decreased their contribution in the respective treatment. The positive effect clearly dominates, and we know this from Result 1, but the values include the direct effect of forcing free riders and low contributors to contribute at least the enforced minimum. Therefore, in Tables 4 and 5 we separate out this direct effect (top row) from subjects' behavioral responses to the minimum level, for the exogenous and endogenous treatment, respectively. In the exogenous treatment (Table 4), 23\% of the subjects contributed nothing in the standard public goods experiment and exactly 5 tokens when this was the enforced minimum, and 8\% increased their contribution from 5 to an average of 8.25

\footnotetext{
${ }^{12}$ From here on we drop the four groups in the endogenous treatment in which the majority voted against the minimum level.
} 
tokens under the minimum level, indicating that they were crowded in. Conversely, $12 \%$ of subjects reduced their contribution from an average contribution of 8.83 in the baseline all the way down to the enforced minimum level, and they were thus crowded out by the minimum level. The average contribution of the remaining $49 \%$ was virtually unchanged. The pattern is similar for the endogenous treatment (Table 5), with the main difference that crowding out is stronger: $10 \%$ of the subjects drop from an average of 11.38 all the way down to the enforced minimum of 5 tokens. By and large, crowding in seems to occur mainly at low levels of standard public goods contributions, which perhaps was caused by pessimistic conditional contributors, whereas crowding out is more likely for subjects who already contribute substantially to the public good. However, for many subjects, the average contribution is rather stable and thus the main share of the positive overall minimum-level effect demonstrated in Table 1 comes from the direct effect of pushing free riders and low contributors up to the minimum level. For behavioral responses beyond this, the net effect is more or less zero on average.

\section{Insert Tables 3, 4, and 5 about here}

Result 5. Minimum contribution levels effectively work on the extensive margin; there is no evidence that it will serve to crowd out voluntary contributions to the public good.

Previous empirical research has suggested that a large fraction of people are conditional cooperators, i.e., they cooperate if others cooperate and vice versa (e.g., Fischbacher et al., 2001). The unconditional results in Table 2 indicate a correlation between contributions and beliefs. In Figures 3 and 4, we explore how contributions match beliefs about others' contributions. The difference in contributions between the MCL public goods experiment and the standard public goods experiment (y-axis) is plotted against the corresponding difference in beliefs about others' contributions (x-axis). On average, individuals who believe that the aggregate public good provision will increase also increase their own contribution. For those who instead believe in a reduction of contributions, the opposite is true, i.e., they decrease their own contribution. Behavior in our experiment is thus consistent with the notion of conditional cooperation. 
The other part of the public goods experiment elicited conditional contributions. ${ }^{13}$ Conditional contributions are elicited using a variant of the strategy method. The main advantage with this procedure is that we can control for subjects' beliefs about others' contributions in an incentive-compatible way using the strategy method and furthermore classify subjects into different contributor types. We can thus in more detail analyze the direct impact of the policy on subjects' cooperative preferences. For instance, those who in the baseline contribute substantially to the public good regardless of others' contributions might shift their schedule downwards due to hidden costs of control; or conditional cooperators might shift their schedule upwards at low levels of others' average contribution if they like the idea that everybody has to contribute to the public good under the new institution. ${ }^{14}$

Figures 5 and 6 show the average conditional contribution for each level of average contribution level of the others separated by treatment, i.e., endogenous and exogenous minimum level, respectively. The average own contributions to the public good (y-axis) are plotted against the conditional average contributions of the other two group members (x-axis), following Fischbacher et al. (2001). As expected, there is an overall positive relationship between own contributions and others' average contributions. These results show that subjects are on average conditional contributors since their own contribution levels increase when the average contributions by others increase. Interestingly, under the minimum contribution level, the slopes of the schedules are approximately the same as for the standard public goods experiment, but there is a shift in levels for a given average contribution by others. This corroborates the finding that minimum provision levels are effective; free riders can be forced to increase their contribution without ex-ante compliers reacting against the control exerted upon the group as a whole. The results hold if beliefs about others' average contributions remain unchanged or do not decrease more than 2-3 tokens.

\section{Insert Figures 5 and 6 about here}

In Table 6, we follow up more closely on the individual data used in Figures 5 and 6. We regress own conditional contributions on others' average contributions. In column 1, we pool

\footnotetext{
${ }^{13}$ One subject in the endogenous treatment contributed less than the required minimum of 5 tokens in the MCL contribution table. Since all entries were below the minimum level, we treat this subject in our analyses as if she had contributed 5 tokens throughout the contribution table.

${ }^{14}$ In experiments, it is well documented that subjects on average bear a strong aversion against free riding. For instance, Cubitt et al. (2011) document that most people view free riding as morally reprehensible, and in games where peer-to-peer punishment is available, the intensity of costly punishment is usually strongly increasing in the receiver's negative deviation from the group’s average contribution (Fehr and Gächter, 2000).
} 
the sample and investigate the impact of the minimum level on the intercept and slope of the regression line, where the latter measures the marginal increase in contribution when others' average contribution increases with one token. The MCL dummy captures the impact of the minimum level. For instance, when the average contribution of the other group members equals 5 tokens, subjects on average report an own contribution of $3.62(1.37+5 \times 0.45)$ tokens in the baseline and this number increases to $5.82(1.37+5 \times 0.45+2.57-5 \times 0.07)$, i.e., by 2.22 tokens, following the implementation of the minimum level. In column 2, we investigate the full within-between dimension of the data, comparing differences between the endogenous and exogenous treatments in the effect of the minimum level on conditional contributions. Neither with respect to intercept (Endo $\times M C L)$ nor slope $($ Endo $\times M C L \times$ Others) is the MCL effect different between the treatments, since the estimated effects are both small and insignificant. Thus, there is no evidence of a more pronounced minimum-level effect in the endogenous treatment vis-à-vis the exogenous treatment, which is in line with previously reported descriptive statistics.

\section{Insert Table 6 about here}

In more detailed analyses, we categorize subjects into contributor types following the convention introduced by Fischbacher et al. (2001). They classified subjects into four types: conditional cooperators, free riders, hump-shaped contributors, and others. ${ }^{15}$ Tables 7 and 8 show the distribution of types both in baseline and with the minimum contribution level, for the exogenous and endogenous treatment, respectively. The tables enable us to investigate type stability, which is related to the discussion about crowding in and crowding out as a behavioral response to the minimum-level institution, and again we can analyze this issue while controlling for beliefs about others’ behavior.

Most notably, in both treatments, the share of conditional cooperators decreases whereas the share of free riders increases. For example, in the exogenous treatment (Table 7), the share of free riders increases from $17.65 \%$ in the baseline to $25.49 \%$ under the minimum level; 5.88 of this 7.84 percentage point increase constitute baseline conditional cooperators. Of the $64.7 \%$

\footnotetext{
${ }^{15}$ Based on their conditional contribution schedule, we define types as follows: Conditional cooperators have either a weakly increasing schedule or the Spearman correlation (with the others' average contribution) is positive and significant at the 1\% level; free riders always contribute the lowest amount allowed; hump-shaped contributors display a positive (negative) Spearman correlation up to (beyond) their highest contribution, both significant at the 1\% level; and "others" do not fit into any of these categories. For a discussion on classification, see, e.g., Fischbacher et al. (2001).
} 
baseline conditional cooperators, only 52.94 percentage points remain under the minimum level. The pattern is very similar in the endogenous treatment. To fully account for behavioral responses, we also present, in Table 9, the type distribution when the types in the baseline are characterized after we manually adjust all subjects up to the minimum of 5 tokens in the standard public goods experiment. Thus, any remaining effect comes from subjects' behavioral reaction to the implementation of the minimum level. Interestingly, when we characterize baseline types in relation to the adjusted minimum level, contributor types are remarkably stable across baseline and the minimum-level institution. For example, when a baseline free rider is characterized as someone who never contributes above 5 tokens (rather than someone who never contributes above 0 tokens), there are $25.49 \%$ free riders already in the exogenous baseline and thus there is no aggregate increase in the share of free riders when we measure types in this way. In the endogenous treatment, there is a 3.70 percentage point increase in the share of free riders, but this is a substantially smaller rise than the 16.05 percentage point increase we observe in Table 8 when we use the normal type characterization without the adjustment of a minimum level of 5 tokens in the standard public goods experiment. Thus, the change in type distribution brought about by the minimum level seems to be an artefact of the minimum level automatically classifying weak contributors as free riders. ${ }^{16}$ In conjunction with the regression results in Table 6 , the absence of treatmentdriven differences in the distribution of contribution types supports our main conclusion regarding the impact of endogenous institution formation on cooperative preferences.

\section{Insert Tables 7, 8 and 9 about here}

Result 6. Allowing groups to decide for themselves whether or not a minimum provision level should be implemented does not make individuals more cooperative. Vis-à-vis exogenous implementation, the opportunity to vote does not affect subjects' cooperative preferences.

\section{Discussion and conclusion}

In this paper, we investigate the effect of imposing a minimum contribution level on cooperative behavior. A centralized institution with exogenous imposition of rules and regulations of minimum levels is in many cases the only feasible option for policy makers since letting individuals themselves be responsible for punishment, rewards, and potentially

\footnotetext{
${ }^{16}$ For instance, a conditional contributor with a positive contribution schedule that never reaches above 5 tokens would be classified as a free rider in Table 9 once the minimum level has been implemented.
} 
ostracizing others is not possible in many situations, including taxation and environment. Without considering behavioral responses, we would expect an imposed minimum contribution level to increase cooperation levels if the society consists of free riders or subjects who contribute a small amount. However, imposing a minimum level might add an additional control cost as discussed by Falk and Kosfeld (2006), which could result in reduced contributions to the public good among subjects who already contributed above the imposed minimum level. Previous research has also shown that it is not only the introduction of an institution per se that might affect behavior, but also the way it is introduced (e.g., Dal Bó et al., 2010; Markussen et al., 2014a; Sutter et al., 2010; Tyran and Feld, 2006).

The objective of this paper was to investigate, by using a public goods experiment, the effect of (i) imposing a minimum level of contribution to a public good and (ii) the mode of implementation, i.e., whether the way in which the minimum level is introduced, either endogenously by majority voting or exogenously, affects contributions.

We believe that a low minimum level, which we in our experiment set to $25 \%$ of the endowment, is the most feasible policy option since too high exogenous minimum levels would be met with resistance since people differ in terms of their preferences, their endowments, and in some cases also in their costs of contributing to the public good, e.g., costs of effort. In addition, too high endogenous minimum levels would likely be opposed and voted down for the same reasons. An alternative could be to introduce non-binding minimum levels, but empirical evidence indicates that non-binding announcements and promises have little or no effect on voluntary contributions to public goods (e.g., Bochet and Putterman, 2009).

Overall, our results show that a minimum contribution level has a positive and sizeable effect on cooperation whether imposed exogenously or endogenously. This positive effect is mainly due to the fact that free riders are forced to increase their contribution, while at the same time the contributions by those who originally contributed above the imposed minimum level were not crowded out. In the context of cooperation, there does not seem to be a hidden cost of control. This is probably linked to the fact that imposing a minimum level actually has a potentially positive welfare effect per se, while in the case of Falk and Kosfeld (2006) the control mechanism is directly linked to distrust. However, we cannot rule out a spillover effect of the imposed minimum level in one area on other areas with clearer elements of trust, which would then be an indirect negative welfare effect of the policy. 
Our findings are robust to whether the minimum contribution level is imposed exogenously or endogenously by voting. Thus, the overall effect of majority voting as a signal of cooperation does not seem to be strong in this context. An explanation is that there is an incentive for selfish players to vote in favor of the minimum level, since it has a potentially positive welfare effect per se, which makes it difficult for intrinsically cooperative individuals to signal their cooperative intentions by voting yes. By comparison, in Tyran and Feld (2006), voting for a non-deterrent law of full contribution is a strong signal of cooperative intentions since selfish players would vote no unless they think that there are conditional cooperators in the group who would take a yes vote as a signal of cooperative intentions. Likewise, in Dal Bó et al. (2010), the only reason a selfish player would vote to impose a fine on unilateral defection in a prisoners' dilemma game would be to use it as a "bait strategy,” i.e., to signal that one intends to cooperate when in reality one plans to defect (since the payoff from defection is higher if the other player cooperates). Similarly, in Sutter et al. (2010) and Markussen et al. (2014a), subjects voting in favor of introducing peer-to-peer punishment signal their intention to make use of this mechanism in order to enforce higher levels of cooperation. To summarize, the main difference between our paper and for instance the four papers discussed above is that even if nobody wants to cooperate, there is still an incentive to vote yes in our setting. This is not the case in any of the other papers.

Still, there could be reasons beyond signaling for why individuals cooperate more under endogenous institutions. Dal Bó et al. (2010) discuss the establishment of a cooperative norm and coordination as possible reasons beyond signaling, and furthermore show that signaling is not the main driver behind a sizeable effect of democratically chosen institutions on cooperation in their setting. In our setting, one such effect could be that endogenous formation of institutions reduces the hidden costs of control and thus has a legitimizing effect on ex-post cooperation. The likely explanation for an absence of such an effect is that a hidden cost of control seems not to be pervasive in the context of cooperation. The societal welfare effect of a minimum-level policy depends on a number of factors, including the perceived control cost and the signaling effect of voting in favor of imposing the minimum level. An important ingredient for the welfare effect is the composition of contributor types, and how the above mentioned policy variables affect this composition. Societies with a high fraction of free riders or where there is a strong and positive signal of increased contributions when imposing a minimum level will clearly benefit from the policy, while the opposite might hold for societies with high trust levels and a large fraction of conditional cooperators. Since minimum 
levels are used in many areas of society, it is important to understand their welfare effects, especially considering that the imposed minimum level often is low.

\section{Acknowledgements}

We are grateful to Martin Kocher for valuable comments and suggestions. We thank seminar and conference participants at the University of Gothenburg, the 2014 ESA European meeting, and the 9th Nordic Conference on Behavioral and Experimental Economics for helpful comments and discussion. Financial support from Formas through the Human Cooperation to Manage Natural Resources (COMMONs) program and from the Swedish Research Council (Vetenskapsrådet, ref 348 2013-6348) is gratefully acknowledged. We would also like to thank assistant experimenters Lisa Björk and Andrea Martinangeli. 


\section{References}

Andreoni, J. (1989). Giving with impure altruism: applications to charity and Ricardian equivalence. Journal of Political Economy, 97, 1447-1458.

Andreoni, J. (1990). Impure altruism and donations to public goods: a theory of warm-glow giving. Economic Journal, 100, 464-477.

Andreoni, J. (1993). An experimental test of the public-goods crowding-out hypothesis. American Economic Review, 83, 1317-1327.

Bergstrom, T., Blume, L., \& Varian, H. (1986). On the private provision of public goods. Journal of Public Economics, 29, 25-49.

Bochet, O., \& Putterman, L. (2009). Not just babble: opening the black box of communication in a voluntary contribution experiment. European Economic Review, 53, 309-326.

Chan, K.S., Godby, R., Mestelman, S., \& Muller, R.A. (2002). Crowding-out voluntary contributions to public goods. Journal of Economic Behavior \& Organization, 48, 305-317.

Chaudhuri, A. (2011). Sustaining cooperation in laboratory public goods experiments: a selective survey of the literature. Experimental Economics, 14, 47-83.

Cubitt, R.P., Drouvelis, M., Gächter, S., \& Kabalin, R. (2011). Moral judgments in social dilemmas: how bad is free riding? Journal of Public Economics, 95, 253-264.

Dal Bó, P. (2014). Experimental evidence on the workings of democratic institutions. In Galiani, S., \& Sened, I. (Eds.), Institutions, Property Rights, and Economic Growth: The Legacy of Douglass North (pp. 266-288). Cambridge University Press.

Dal Bó, P., Foster, A., \& Putterman, L. (2010). Institutions and behavior: experimental evidence on the effects of democracy. American Economic Review, 100, 2205-2229.

Dannenberg, A. (2012). Coalition formation and voting in public goods games. Strategic Behavior and the Environment, 2, 83-105.

Dannenberg, A., Lange, A., \& Sturm, B. (2014). Participation and commitment in voluntary coalitions to provide public goods. Economica, 81, 257-275. 
Ertan, A., Page, T., \& Putterman, L. (2009). Who to punish? Individual decisions and majority rule in mitigating the free rider problem. European Economic Review, 53, 495-511.

Falk, A., \& Kosfeld, M. (2006). The hidden costs of control. American Economic Review, 96, $1611-1630$.

Fehr, E., \& Gächter, S. (2000). Cooperation and punishment in public goods experiments. American Economic Review, 90, 980-994.

Fischbacher, U., Gächter, S., \& Fehr, E. (2001). Are people conditionally cooperative? Evidence from a public goods experiment. Economics Letters, 71, 397-404.

Galbiati, R., \& Vertova, P. (2008). Obligations and cooperative behavior in public good games. Games and Economic Behavior, 64, 146-170.

Gallier, C., Kesternich, M., \& Sturm, B. (2014). Voting for burden sharing rules in public goods games. ZEW Discussion Paper 14-056.

Gerber, A., Neitzel, J., \& Wichardt, P. (2013). Minimum participation rules for the provision of public goods. European Economic Review, 64, 209-222.

Greiner, B. (2015). Subject pool recruitment procedures: organizing experiments with ORSEE. Journal of the Economic Science Association, 1, 114-125.

Gronberg, T.J., Luccasen III, R.A., Turocy, T.L., \& Van Huyck, J.B. (2012). Are tax-financed contributions to a public good completely crowded-out? Experimental evidence. Journal of Public Economics, 96, 596-603.

Henrich, J., Heine, S.J., \& Norenzayan, A. (2010). The weirdest people in the world? Behavioral and Brain Sciences, 33, 61-135.

Kamei, K., Putterman, L., \& Tyran, J.-R. (2015). State or nature? Endogenous formal versus informal sanctions in the voluntary provision of public goods. Experimental Economics, 18, 38-65.

Keser, C., Markstädter, A., \& Schmidt, M. (2014). Mandatory minimum contributions, heterogeneous endowments and voluntary public-good provision. CIRANO Scientific Series 2014s-47. 
Kesternich, M., Lange, A., \& Sturm, B. (2014a). On the performance of rule-based contribution schemes under endowment heterogeneity. ZEW Discussion Paper 14-055.

Kesternich, M., Lange, A., \& Sturm, B. (2014b). The impact of burden sharing rules on the voluntary provision of public goods. Journal of Economic Behavior \& Organization 105, 107-123.

Kocher, M, Martinsson, P., Persson, E., \& Wang, X. (2016). Is there a hidden cost of imposing a minimum contribution level for public good contributions? Working Paper 654, Department of Economics, University of Gothenburg.

Kosfeld, M., Okada, A., \& Riedl, A. (2009). Institution formation in public goods games. American Economic Review, 99, 1335-1355.

Kroll, S., Cherry, T.L., \& Shogren, J.F. (2007). Voting, punishment, and public goods. Economic Inquiry, 45, 557-570.

Markussen, T., Putterman, L., \& Tyran, J.R. (2014a). Self-organization for collective action: an experimental study of voting on sanction regimes. Review of Economic Studies, 81, 301324.

Markussen, T., Reuben, E., \& Tyran, J.R. (2014b). Competition, cooperation and collective choice. Economic Journal, 124, 163-195.

Putterman, L., Tyran, J.R., \& Kamei, K. (2011). Public goods and voting on formal sanction schemes. Journal of Public Economics, 95, 1213-1222.

Riedel, N., \& Schildberg-Hörisch, H. (2013). Asymmetric obligations. Journal of Economic Psychology, 35, 67-80.

Sefton, M., Shupp, R., \& Walker, J. (2007). The effect of rewards and sanctions in provision of public goods. Economic Inquiry, 45, 671-690.

Sutter, M., Haigner, S., \& Kocher, M.G. (2010). Choosing the carrot or the stick? Endogenous institutional choice in social dilemma situations. Review of Economics Studies, 77, 15401566.

Sutter, M., \& Weck-Hannemann, H. (2004). An experimental test of the public-goods 
crowding-out hypothesis when taxation is endogenous. Finanzarchiv, 60, 94-110.

Tyran, J.R., \& Feld, L.P. (2006). Achieving compliance when legal sanctions are nondeterrent. Scandinavian Journal of Economics, 108, 135-156.

Warr, P.G. (1982). Pareto optimal redistribution and private charity. Journal of Public Economics, 19, 131-138.

Zelmer, J. (2003). Linear public goods experiments: a meta-analysis. Experimental Economics, 6, 299-310.

Ziegelmeyer, A., Schmelz, K., \& Ploner, M. (2012). Hidden costs of control: four repetitions and an extension. Experimental Economics, 15, 323-340. 


\section{Tables and figures}

Table 1 Results from the public goods experiments: unconditional contributions

\begin{tabular}{lccc}
\hline Treatment & Standard & MCL $^{\mathrm{a}}$ & $\begin{array}{c}\mathrm{H}_{0}: \\
\text { Standard=MCL } \\
(\mathrm{p} \text {-values) }\end{array}$ \\
\hline Exogenous $(n=51)$ & $8.35(6.80)$ & $9.43(5.47)$ & 0.01 \\
Endogenous $(n=93)$ & $8.24(7.00)$ & $9.09(5.68)$ & $<0.01$ \\
\hline
\end{tabular}

Note: Standard deviations in brackets. $n=$ number of subjects. ${ }^{a}$ For subjects in groups rejecting the endogenous minimum level, the minimum level is not imposed in the second stage; instead they participate in a standard public goods experiment.

Table 2 Voting behavior in the endogenous treatment

\begin{tabular}{lcccccc}
\hline & $\begin{array}{c}\text { Standard } \\
\text { contr. }\end{array}$ & $\begin{array}{c}\text { Standard } \\
\text { belief }\end{array}$ & $\begin{array}{c}\text { MCL } \\
\text { contr. }\end{array}$ & $\begin{array}{c}\text { MCL } \\
\text { belief }\end{array}$ & $\begin{array}{c}\mathrm{H}_{0} \text { : Standard } \\
\text { contr.=MCL } \\
\text { contr. (p-values) }\end{array}$ & $\begin{array}{c}\mathrm{H}_{0} \text { : Standard } \\
\text { contr. } \\
\text { Standard belief } \\
\text { (p-values) }\end{array}$ \\
\hline $\begin{array}{l}\text { Exogenous } \\
(n=51)\end{array}$ & 8.35 & 7.76 & 9.43 & 9.57 & 0.01 & $<0.01$ \\
$\begin{array}{l}\text { Endogenous } \\
(n=93)\end{array}$ & 8.25 & 7.66 & 9.09 & 9.01 & $<0.01$ & $<0.01$ \\
& & & & & & \\
Endogenous: own & & & & & & \\
and group vote & & & & & & \\
-Yes/Yes $(n=72)$ & 8.39 & 7.43 & 9.75 & 9.54 & $<0.01$ & 0.01 \\
- - No/Yes $(n=9)$ & 8.22 & 8.89 & 6.67 & 7.78 & 0.63 & 0.37 \\
- - No/No $(n=9)$ & 8.44 & 9.22 & 7.78 & 7.78 & 0.16 & 0.17 \\
- Yes/No $(n=3)$ & 4.33 & 4.67 & 4.33 & 3.67 & &. \\
\hline
\end{tabular}

Table 3 Behavioral response to imposing the minimum level

\begin{tabular}{lccc}
\hline & $\begin{array}{c}\text { Higher in } \\
\text { MCL }\end{array}$ & $\begin{array}{c}\text { No } \\
\text { difference }\end{array}$ & $\begin{array}{c}\text { Lower in } \\
\text { MCL }\end{array}$ \\
\hline Exogenous $(n=51)$ & $49 \%$ & $31 \%$ & $20 \%$ \\
Endogenous $(n=81)$ & $43 \%$ & $40 \%$ & $17 \%$ \\
& & & \\
Endogenous: own & & & \\
and group vote & & & \\
-Yes/Yes $(n=72)$ & $44 \%$ & $42 \%$ & $14 \%$ \\
- No/Yes $(n=9)$ & $33 \%$ & $22 \%$ & $44 \%$ \\
\hline
\end{tabular}


Table 4 Behavioral response to imposing the minimum level for exogenous treatment ( $\mathrm{n}=$ 51)

\begin{tabular}{ccccc}
\hline $\begin{array}{c}\text { Contributions in } \\
\text { standard public } \\
\text { goods } \\
\text { experiment }\end{array}$ & $\begin{array}{c}\text { Contributions in } \\
\text { MCL public } \\
\text { goods } \\
\text { experiment }\end{array}$ & $\begin{array}{c}\text { Proportion of } \\
\text { subjects }\end{array}$ & $\begin{array}{c}\text { Average } \\
\text { contribution in } \\
\text { standard public } \\
\text { goods experiment }\end{array}$ & $\begin{array}{c}\text { Average } \\
\text { contribution in } \\
\text { minimum level } \\
\text { public goods } \\
\text { experiment }\end{array}$ \\
\hline $0, \ldots, 4$ & 5 & $23 \%$ & 0.00 & 5.00 \\
$0, \ldots, 4$ & $6, \ldots, 20$ & $2 \%$ & 2.00 & 6.00 \\
5 & 5 & $6 \%$ & 5.00 & 5.00 \\
5 & $6, \ldots, 20$ & $8 \%$ & 5.00 & 8.25 \\
$6, \ldots, 20$ & 5 & $12 \%$ & 8.83 & 5.00 \\
$6, \ldots, 20$ & $6, \ldots, 20$ & $49 \%$ & 13.44 & 13.48 \\
\hline
\end{tabular}

Table 5 Behavioral response to imposing the minimum level for endogenous treatment (yesgroups, $\mathrm{n}=81$ )

\begin{tabular}{ccccc}
\hline $\begin{array}{c}\text { Contributions in } \\
\text { standard public } \\
\text { goods } \\
\text { experiment }\end{array}$ & $\begin{array}{c}\text { Contributions in } \\
\text { MCL public } \\
\text { goods } \\
\text { experiment }\end{array}$ & $\begin{array}{c}\text { Proportion of } \\
\text { subjects }\end{array}$ & $\begin{array}{c}\text { Average } \\
\text { contribution in } \\
\text { standard public } \\
\text { goods experiment }\end{array}$ & $\begin{array}{c}\text { Average } \\
\text { contribution in } \\
\text { minimum level } \\
\text { public goods } \\
\text { experiment }\end{array}$ \\
\hline $0, \ldots, 4$ & 5 & $27 \%$ & 0.10 & 5.00 \\
$0, \ldots, 4$ & $6, \ldots, 20$ & $2 \%$ & 1.50 & 7.50 \\
5 & 5 & $5 \%$ & 5.00 & 5.00 \\
5 & $6, \ldots, 20$ & $5 \%$ & 5.00 & 8.25 \\
$6, \ldots, 20$ & 5 & $10 \%$ & 11.38 & 5.00 \\
$6, \ldots, 20$ & $6, \ldots, 20$ & $51 \%$ & 13.22 & 13.27 \\
\hline
\end{tabular}


Table 6 Cooperative preferences by treatment (linear regression)

Dependent variable:

(1)

(2)

Conditional contribution

\begin{tabular}{lcc}
\hline & $1.37(0.40)^{* * *}$ & $1.53(0.75)^{* *}$ \\
Constant & $0.45(0.04)^{* * *}$ & $0.44(0.06)^{* * *}$ \\
Others & $2.57(0.34)^{* * *}$ & $2.05(0.64)^{* * *}$ \\
MCL & $-0.07(0.03)^{* *}$ & $-0.03(0.04)$ \\
MCL $\times$ Others & - & $-0.26(0.88)$ \\
Endo & - & $-0.02(0.08)$ \\
Endo $\times$ Others & - & $0.84(0.74)$ \\
Endo $\times$ MCL & - & $-0.06(0.06)$ \\
Endo $\times$ MCL $\times$ Others & & \\
& 4889 & 4889 \\
\hline Observations & 132 & 132 \\
\hline - Clusters
\end{tabular}

Note: Robust standard errors clustered on individuals (in brackets). Others is the average contribution of the others in the group, $M C L$ is a dummy for the second stage when the minimum level is imposed, and Endo is a dummy for the endogenous treatment. The dependent variable is individual $i$ 's conditional contribution, both in the baseline and with the minimum provision level. ${ }^{* * *}$ denotes significance at the $1 \%$ level, ${ }^{* *}$ significance at the $5 \%$ level, and * significance at the $10 \%$ level.

Table 7 Distribution of contributor types for exogenous treatment $(n=51)$

\begin{tabular}{r|llll|l}
\hline MCL & Conditional & $\begin{array}{l}\text { Free riders } \\
(=5)\end{array}$ & $\begin{array}{l}\text { Hump- } \\
\text { shaped }\end{array}$ & Others & \\
\hline $\begin{array}{l}\text { Conditional } \\
\text { cooperators }\end{array}$ & $50.98 \%$ & $5.88 \%$ & $0.00 \%$ & $7.84 \%$ & $64.70 \%$ \\
$\begin{array}{c}\text { Free (=0) } \\
\text { riders (=5) }\end{array}$ & $0.00 \%$ & $17.65 \%$ & $0.00 \%$ & $0.00 \%$ & $17.65 \%$ \\
$\begin{array}{l}\text { Hump- } \\
\text { shaped }\end{array}$ & $0.00 \%$ & $0.00 \%$ & $0.00 \%$ & $1.96 \%$ & $1.96 \%$ \\
Others & $1.96 \%$ & $1.96 \%$ & $0.00 \%$ & $11.76 \%$ & $15.69 \%$ \\
\hline & & & & & \\
\hline
\end{tabular}

Note: Type definition follows Fischbacher et al. (2001). Conditional cooperators: increasing schedule or positive Spearman correlation (with others' average contribution) at $1 \%$; free riders: contribute the lowest amount allowed; hump-shaped: positive (negative) Spearman correlation at 1\% up to (beyond) their highest contribution. 
Table 8 Distribution of contributor types for endogenous treatment (yes-groups, $n=81$ )

\begin{tabular}{r|lllll|l}
\hline \multicolumn{2}{r|}{ MCL } & $\begin{array}{l}\text { Conditional } \\
\text { Standard }\end{array}$ & $\begin{array}{l}\text { Free riders } \\
\text { cooperators } \\
(=5)\end{array}$ & $\begin{array}{l}\text { Hump- } \\
\text { shaped }\end{array}$ & Others & \\
\hline $\begin{array}{l}\text { Conditional } \\
\text { cooperators }\end{array}$ & $41.98 \%$ & $9.88 \%$ & $1.23 \%$ & $6.17 \%$ & $59.26 \%$ \\
$\begin{array}{l}\text { Free (=0) } \\
\text { riders (=5) }\end{array}$ & $0.00 \%$ & $13.58 \%$ & $0.00 \%$ & $1.23 \%$ & $14.81 \%$ \\
$\begin{array}{l}\text { Hump- } \\
\text { shaped } \\
\text { Others }\end{array}$ & $2.47 \%$ & $1.23 \%$ & $2.47 \%$ & $1.23 \%$ & $7.41 \%$ \\
\hline
\end{tabular}

Note: Type definition follows Fischbacher et al. (2001). Conditional cooperators: increasing schedule or positive Spearman correlation (with others' average contribution) at 1\%; free riders: contribute the lowest amount allowed; hump-shaped: positive (negative) Spearman correlation at 1\% up to (beyond) their highest contribution.

Table 9 Distribution of contributor types when a minimum level is manually imposed on the data from the standard public goods experiment

\begin{tabular}{lcccc}
\hline & \multicolumn{2}{c}{$\begin{array}{c}\text { Exogenous } \\
(n=51)\end{array}$} & \multicolumn{2}{c}{$\begin{array}{c}\text { Endogenous } \\
\text { (yes-groups, } n=81)\end{array}$} \\
& Standard & MCL & Standard & MCL \\
\hline Conditional cooperators & $56.86 \%$ & $52.94 \%$ & $54.32 \%$ & $46.91 \%$ \\
Free riders (=5) & $25.49 \%$ & $25.49 \%$ & $27.16 \%$ & $30.86 \%$ \\
Hump-shaped & $1.96 \%$ & $0.00 \%$ & $6.17 \%$ & $3.70 \%$ \\
Others & $15.69 \%$ & $21.57 \%$ & $12.35 \%$ & $18.52 \%$ \\
\hline
\end{tabular}

Note: Type definition follows Fischbacher et al. (2001). In this table we define contributor types in the standard public goods game are after we manually adjust all subjects up to the minimum of 5 tokens in the standard public goods experiment. This implies that someone who never contributes above 5 tokens in the standard public goods experiment is characterized as a free rider. 
Fig. 1 Individual contributions in exogenous treatment $(n=51)$

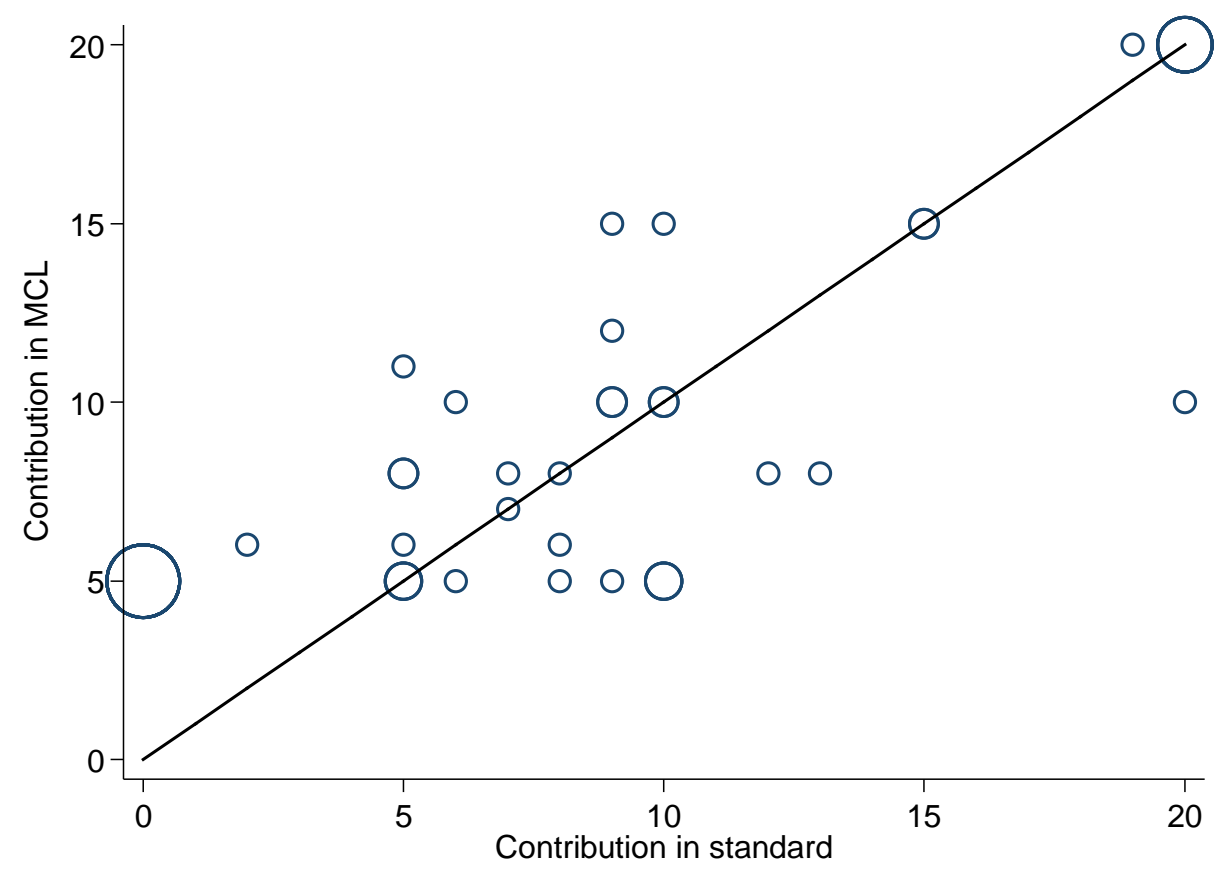

Fig. 2 Individual contributions in endogenous treatment $(n=81)$

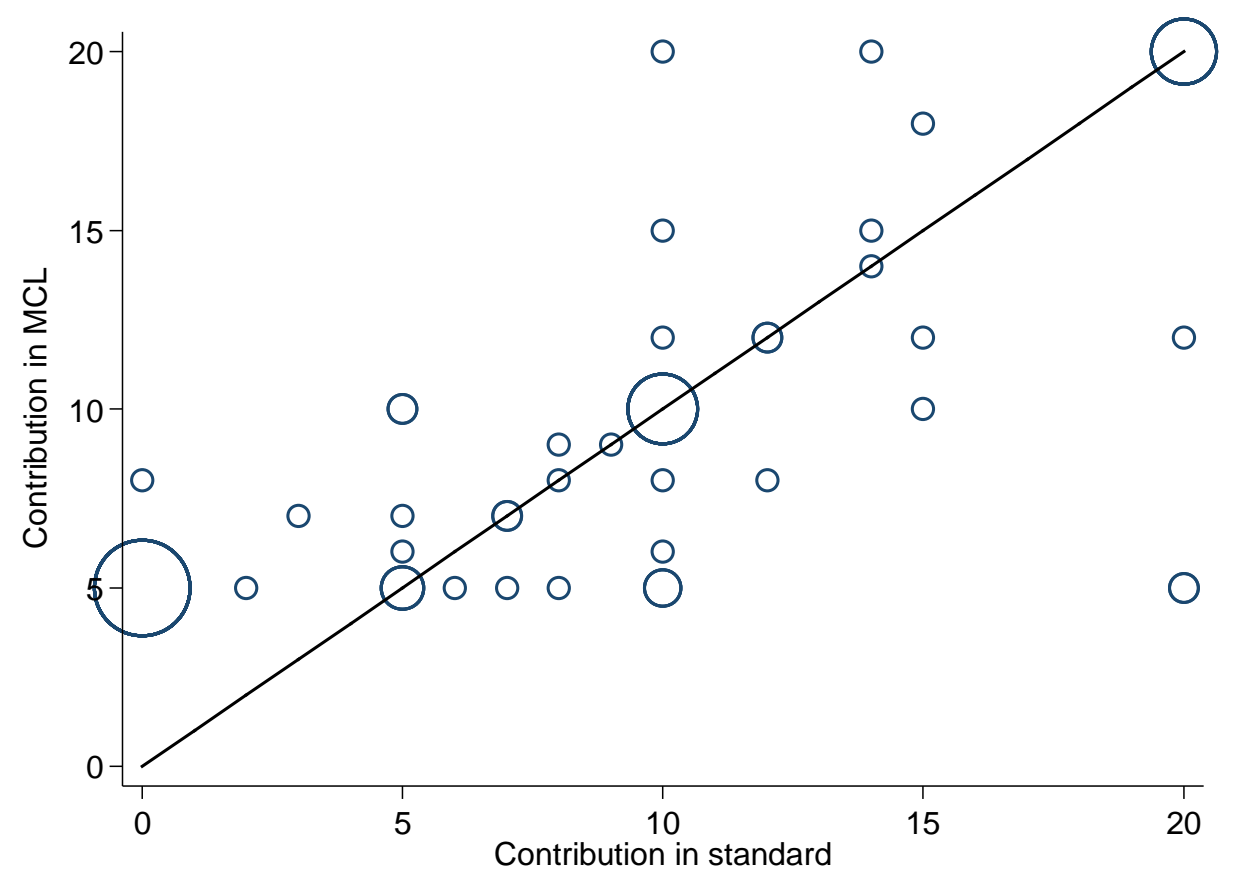


Fig. 3 Contributions and beliefs about others' contributions for exogenous treatment $(n=51)$

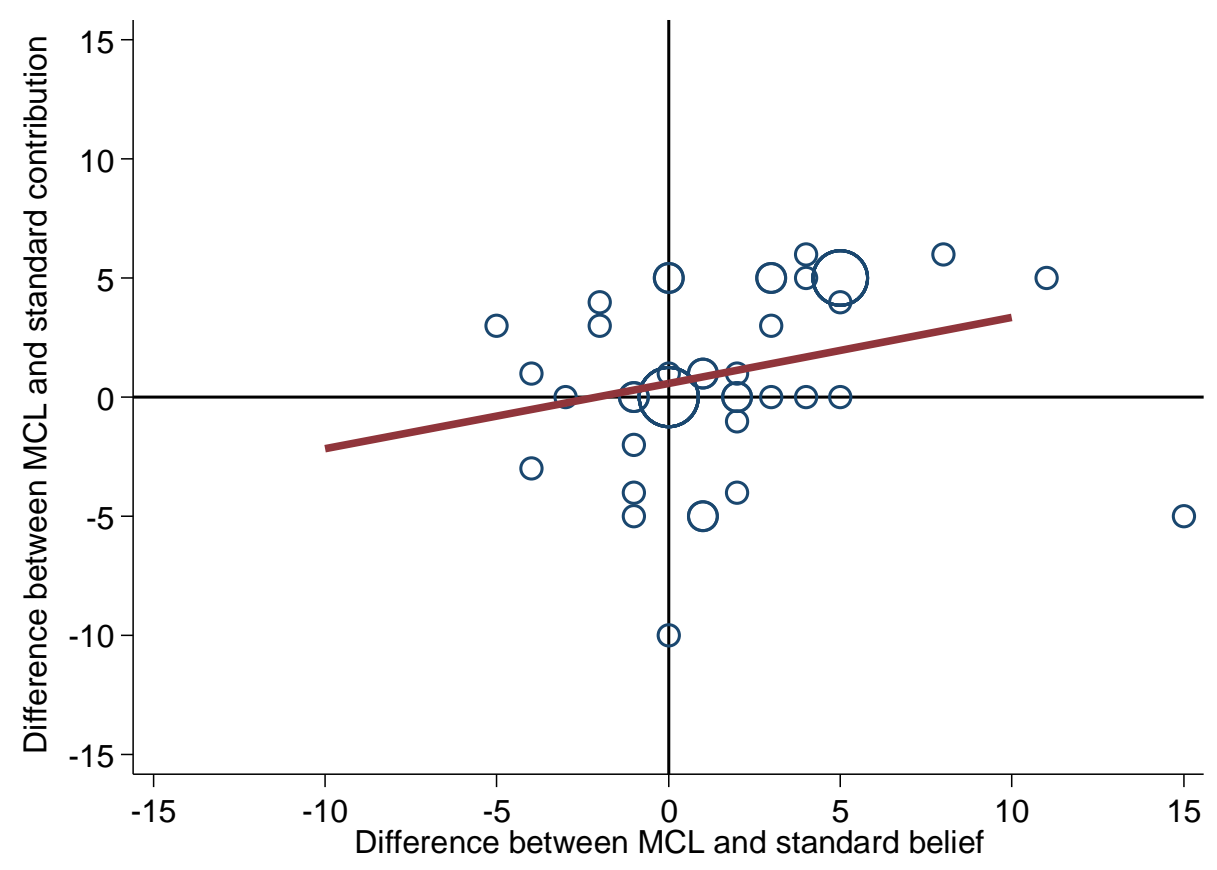

Fig. 4 Contributions and beliefs about others' contributions for endogenous treatment $(n=81)$

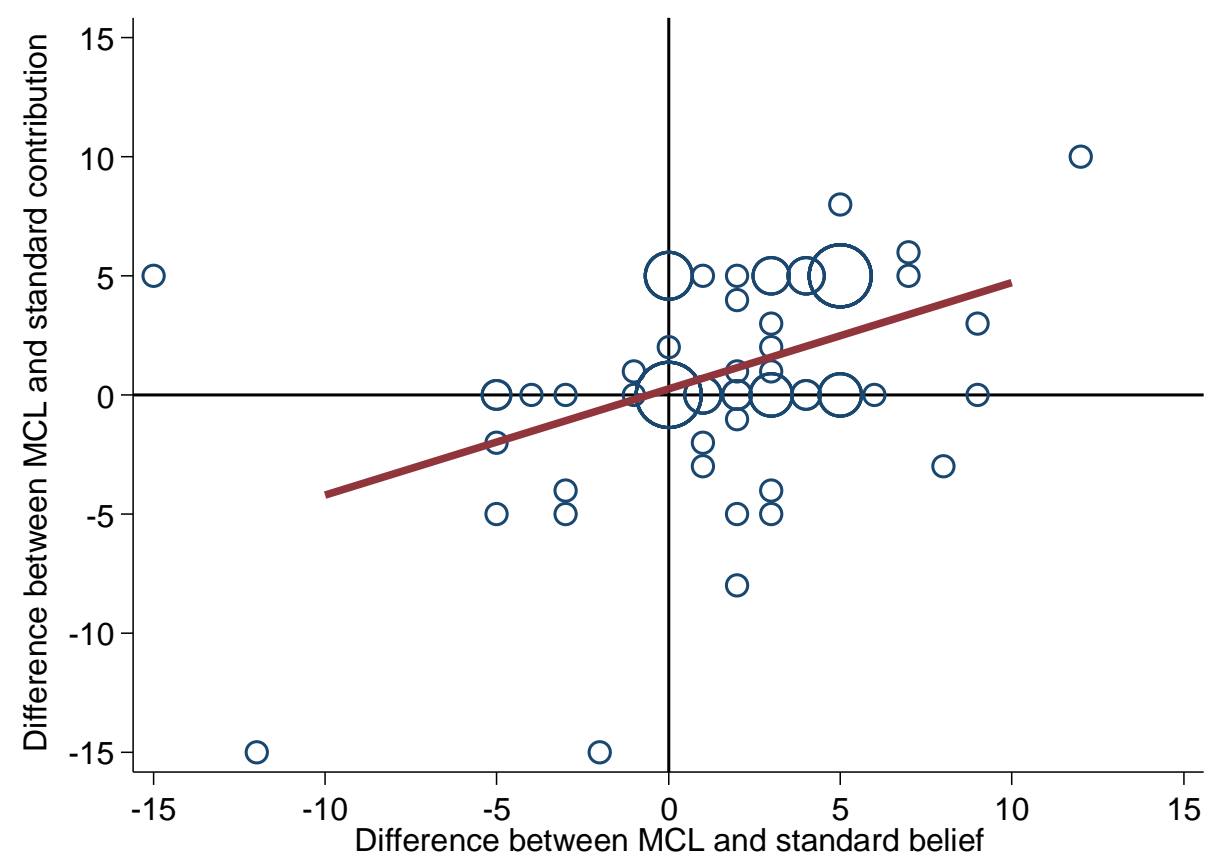


Fig. 5 Average conditional contributions for exogenous treatment $(n=51)$

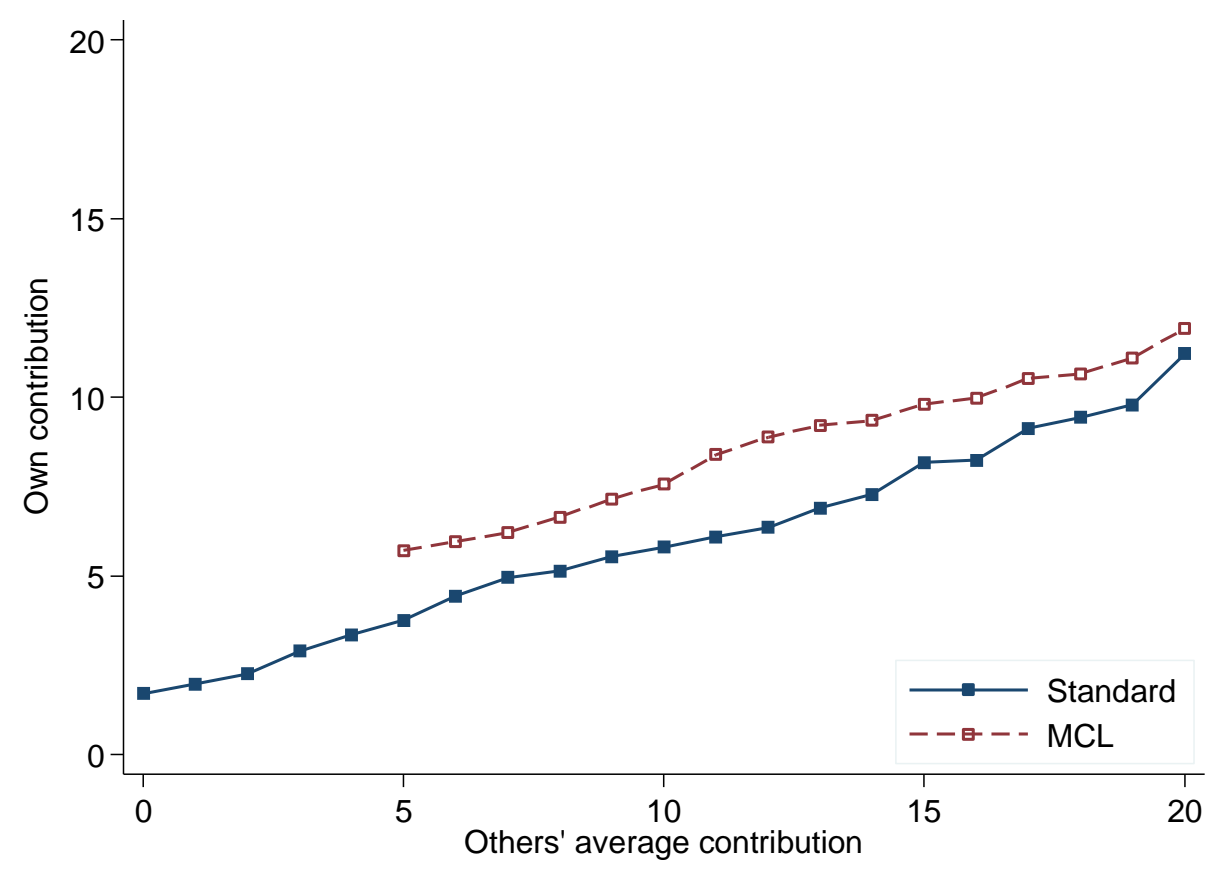

Fig. 6 Average conditional contributions for endogenous treatment $(n=81)$

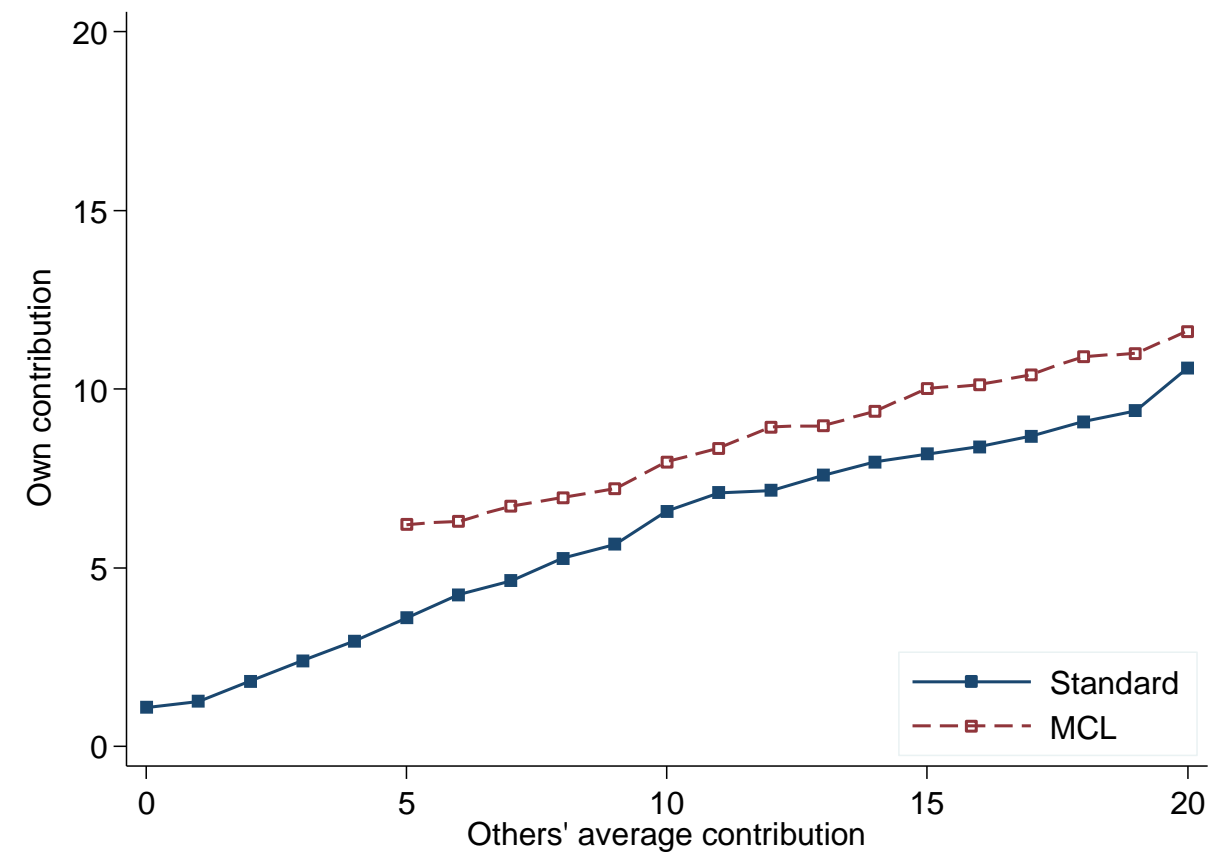

